\title{
Diagnóstico de Câncer de Mama Através de Vetores de Descritores Localmente Agregados
}

\author{
Ricardo Costa da Silva Marques ${ }^{1}$, Geovane Menezes Ramos Neto ${ }^{1}$, \\ Geraldo Braz Júnior ${ }^{1}$, João Dallyson de Sousa Almeida ${ }^{1}$
}

\author{
${ }^{1}$ Núcleo de Computação Aplicada - Laboratório de Mídias Interativas \\ Universidade Federal do Maranhão (UFMA) Campus do Bacanga - São Luís - MA \\ \{rikardomarques, geovane, geraldo, dallyson\}enca.ufma.br
}

\begin{abstract}
An approach to early detect such breast anomalies is the mammography image. However, complex image patterns and the different organization of the breast tissues requires skill and experience by a trained physician to avoid faults in the mammograms interpretation. The main goal of this work is reduces the number of faults associateds to exam. For this, we propose a feature extraction of texture using Vector of Locally Aggregated Descriptors. Initial tests have achieved promising results, the better values obtained with 600 samples of DDSM base are: 90.18 (accuracy), 91.83 (sensitivity) and 94.02 (specificity).
\end{abstract}

\begin{abstract}
Resumo. Uma abordagem para detectar precocemente anomalias na mama é a imagem de mamografia. No entanto, os padrões de imagem complexos e a diferente organização dos tecidos mamários requer habilidade e experiência de médicos treinados para evitar falhas na interpretação de mamografias. $O$ objetivo principal deste trabalho é diminuir esse número de falhas associadas ao exame. Para isso, propomos uma extração de características de textura usando Vetores de Descritores Localmente Agregados. Os testes iniciais alcançaram resultados promissores, os melhores valores obtidos com 600 amostras da base DDSM são: 90.18 (acurácia), 91.83 (sensibilidade) e 94.02 (especificidade).
\end{abstract}

\section{Introdução}

É o tipo de câncer mais comum entre as mulheres no mundo e no Brasil, depois do de pele não melanoma, respondendo por cerca de $25 \%$ dos casos novos a cada ano. O câncer de mama é raramente detectado em homens, totaliza apenas $1 \%$ do total de casos da doença. Possui estimativa de 57.960 novas ocorrências [INCA 2016].

Por sua vez, a atividade de rastreamento de anomalias através de mamografias, demonstra redução na taxa de mortalidade associada a essa patologia. Entretanto, a sensibilidade desse exame varia diretamente proporcional a qualidade, implicando em falhas.

Nesse raciocínio, baseando-se em algoritmos descritores de pontos chave, a metodologia deste trabalho realiza uma extração de características capaz de prover alto poder discriminatório, ao reconhecer regiões de massa encontradas em ROIs (Region of Interest). Tendo como objetivo principal, a classificação dessas regiões em benignas e malignas, fornecendo ao especialista na área uma segunda opinião a respeito do diagnóstico. 


\section{Metodologia}

A metodologia está subdividida em 4 passos principais (Figura-1): aquisição das imagens, pré-processamento com realce logarítmico para evidenciar regiões suspeitas na ROI, a penúltima etapa, faz a detecção de descritores de textura (SURF - Speeded Up Robust Features), a partir desses descritores criamos o dicionário de palavras visuais (BOW+KMeans), resultando na obtenção do vetor de características localmente agregadas (VLAD - Vector of Locally Aggregated Descriptors) e com a ferramenta AutoWeka é feita a classificação.



Figura 1. Etapas da metodologia: aquisição das imagens, pré-processamento (Realce Logarítmico), extração de características detectando pontos chave e gerando descritores (SURF), para criar o vocabulário de palavras visuais (BOW+KMeans), gerar o vetor de características localmente agregadas (VLAD) e fazer a classificação.

Para pré-processamento, as imagens são submetidas ao Realce Logarítmico [Gonzalez and Woods 2010]. Esta técnica de realce tem como objetivo evidenciar os valores de pixels mais escuros em tons mais claros de cinza, propiciando uma melhor obtenção dos diferentes níveis de quantização.

Após o realce logarítmico, o algoritmo SURF [Bay et al. 2008] identifica pontos chaves e gera descritores de textura. Por via de experimentos, foi possível notar que o algoritmo se comporta de forma mais otimizada diante do problema em questão. Seus parâmetros foram ajustados para gerar descritores de 128 elementos, com 4 oitavas, 2 pirâmides gaussianas iguais dentro de cada oitava, limitado em 400 pontos chave e computando rotações.

Com os descritores das classes adquiridos é gerado o dicionário de palavras visuais (Figura 2). Nessa perspectiva, o KMEANS distingue dentre milhares de características quais irão definir de forma mais compacta cada ROI, para a criação do dicionário.

A partir de agora, o VLAD é aplicado com a finalidade de criar um vetor de tamanho fixo contendo a representação das palavras visuais de uma ROI. Sua criação é feita atribuindo cada descritor da imagem ao elemento mais similar do vocabulário e calculando o valor da diferença de ambos.

Baseando-se no método Fisher Kernel, juntamente com o BOW para a criação do vocabulário [Jégou et al. 2010]. Lembre do passo anterior que usou o Kmeans para agrupar os descritores em clusters e construir um vocabulário de k itens: $C=\left[c_{1}, c_{2}, \ldots c_{k}\right]$. Subtraindo cada descritor x do seu respectivo índice no vocabulário e localizando os vizi- 


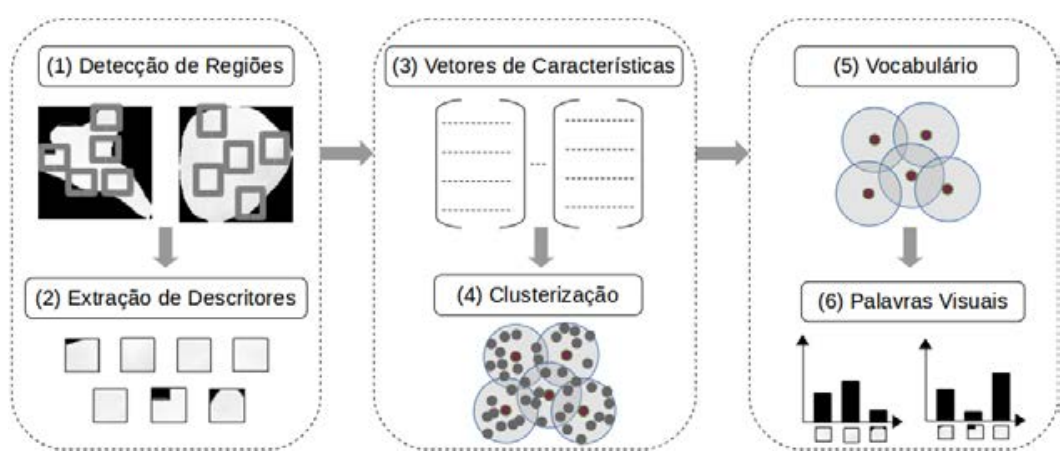

Figura 2. Passos para a obtenção do dicionário de palavras visuais.

nhos mais próximos através do método Nearest Neighbors, foi definido o grau de similaridade.

Portanto, usamos o maior valor $c_{j}$ para calcular as diferenças. Tal que, $c_{j}$ e x possuam número de elementos igual, essa diferença é feita objeto a objeto, e armazenada na posição $c_{j}$ (objeto do vocabulário). Logo, a dimensão D de um VLAD é de $D=$ $(d \times k)$ onde $d$ agrupa todas as características do descritor e $k$ os elementos do vocabulário. Totalizando $k \times d$ características para cada ROI.

Na classificação, utilizamos a ferramenta AUTOWEKA([Thornton et al. 2013]), para criação de 6 experimentos, que elegeram como seletor de atributos e classificador, respectivamente, os algoritmos Best First e Random Forest.

\section{Resultados}

A metodologia está sendo validada com o uso de ROIs da base DDSM [Heath et al. 2000] que contém 1155 amostras, sendo 530 benignas e 625 malignas. Para a realização dos testes iniciais a base foi dividida em duas parcelas com 200 e 600 amostras. Em cada etapa foram utilizados três tamanhos de dicionário: 100, 300 e 500. Por fim, foi feita a separação de $60 \%, 70 \%$ e $80 \%$ dos experimentos para treino, tendo como resultado a média de 5 rounds executados para cada percentual, como mostram as Figuras 3 e 4.

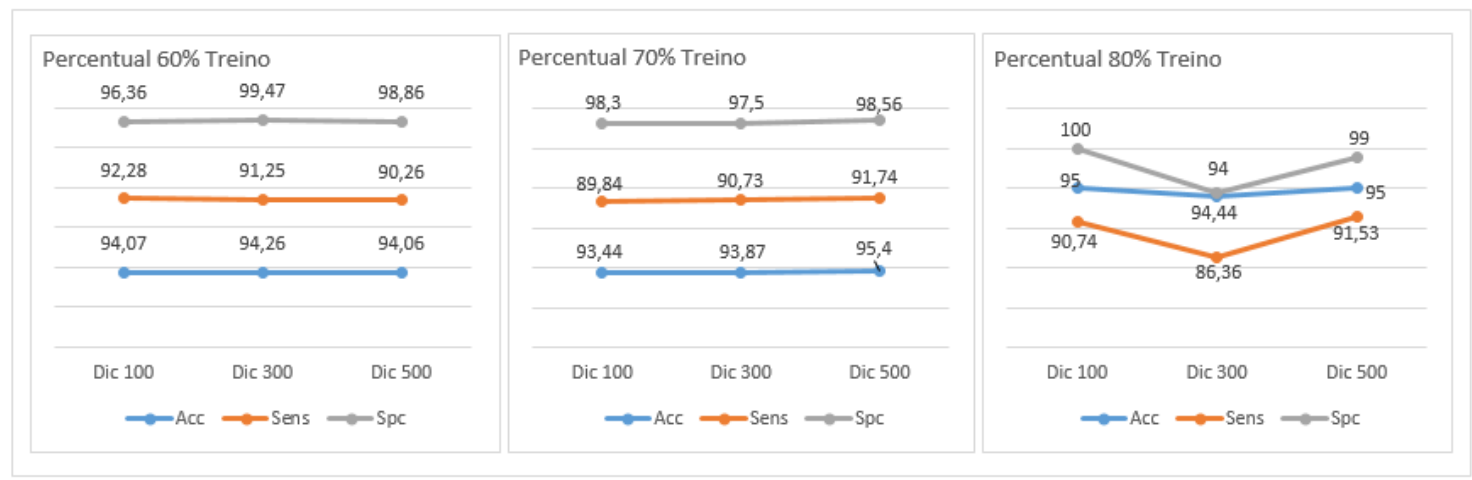

Figura 3. Resultados obtidos para 100 amostras benignas e 100 malignas. 


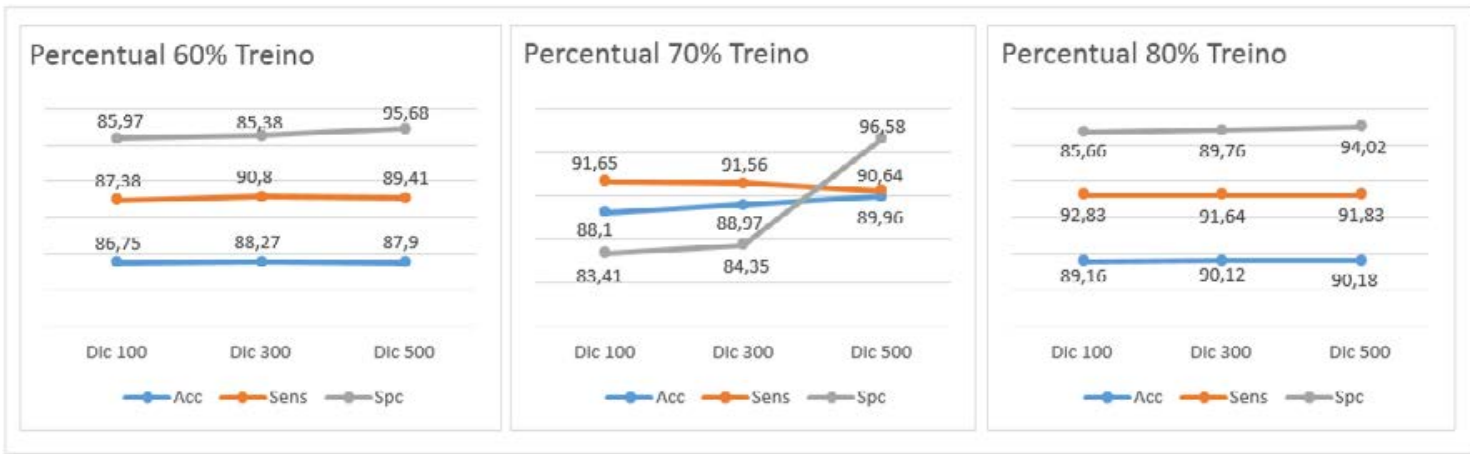

Figura 4. Resultados obtidos para $\mathbf{3 0 0}$ amostras benignas e $\mathbf{3 0 0}$ malignas.

\section{Conclusão e Próximos Passos}

A metodologia aqui mostrada desempenhou um papel bastante aceitável, demonstrando alto poder discriminatório e grande sensibilidade para discernir a respeito de padrões extraídos de regiões de massa. Para dar continuidade ao trabalho, toda a base será submetida a testes para complementar o estudo e para que tenhamos uma visão mais ampla sobre os resultados obtidos. De modo que, o uso de técnicas baseadas em Bag of Words seja analisado com mais clareza, pois notamos que o tamanho do dicionário influencia diretamente na natureza dos resultados.

\section{Agradecimentos}

Os autores desejam agradecer o apoio financeiro concedido pela FAPEMA e CNPq para a execução desta pesquisa.

\section{Referências}

Bay, H., Ess, A., Tuytelaars, T., and Van Gool, L. (2008). Speeded-up robust features (surf). Computer vision and image understanding, 110(3):346-359.

Gonzalez, R. and Woods, R. (2010). Processamento Digital de Imagens. Pearson Prentice Hall, São Paulo, 3 edition.

Heath, M., Bowyer, K., Kopans, D., and Moore, R. (2000). The digital database for screening mammography. Citeseer.

INCA (2016). Estimativas 2016: Incidência de Câncer no Brasil. http://http://www2.inca.gov.br/wps/wcm/connect/tiposdecancer/site/home/mama/.

Jégou, H., Douze, M., Schmid, C., and Pérez, P. (2010). Aggregating local descriptors into a compact image representation. In Computer Vision and Pattern Recognition (CVPR), 2010 IEEE Conference on, pages 3304-3311. IEEE.

Thornton, C., Hutter, F., Hoos, H. H., and Leyton-Brown, K. (2013). Auto-weka: Combined selection and hyperparameter optimization of classification algorithms. In Proceedings of the 19th ACM SIGKDD international conference on Knowledge discovery and data mining, pages 847-855. ACM. 